BMJ Open Sport \& Exercise Medicine

\section{Sildenafil does not reliably improve exercise performance in hypoxia: a systematic review}

To cite: Carter EA, Lohse K, Sheel W, et al. Sildenafil does not reliably improve exercise performance in hypoxia: a systematic review. BMJ Open Sport \& Exercise Medicine 2019;5:e000526. doi:10.1136/ bmjsem-2019-000526

- Additional material is published online only. To view please visit the journal online (http://dx.doi.org/10.1136/ bmjsem-2019-000526).

Accepted 21 February 2019

Check for updates

C) Author(s) (or their employer(s)) 2019. Re-use permitted under CC BY-NC. No commercial re-use. See rights and permissions. Published by BMJ.

${ }^{1}$ Kinesiology, University of British Columbia, Vancouver, British Columbia, Canada

${ }^{2}$ Health-Kinesiology-Recreation, University of Utah, Salt Lake City, Utah, USA

${ }^{3}$ Division of Sports Medicine, University of British Columbia, Vancouver, British Columbia, Canada

Correspondence to Dr Michael Koehle; michael.koehle@ubc.ca

\section{ABSTRACT}

Objective Sildenafil is a pulmonary vasodilator that may reduce the decrement in endurance performance in moderate hypoxia. We assessed the efficacy of sildenafil to improve performance in hypoxia.

Data sources/eligibility Criteria We systematically searched electronic databases (until August 2018) for randomised trials comparing sildenafil with placebo. We also examined the effect of sildenafil on pulmonary artery pressure (PAP), cardiac output (CO) and pulse oxygen saturation $\left(\mathrm{S}_{\mathrm{P}} \mathrm{O}_{2}\right)$ compared with placebo in hypoxia. Fourteen studies were included; 210 subjects received sildenafil 40,50 or $100 \mathrm{mg} /$ day.

Results Sildenafil showed a large effect for decreasing PAP during exercise and at rest, a small effect for increasing $\mathrm{CO}$ during exercise and a moderate effect at rest, a moderate effect for increasing $\mathrm{S}_{\mathrm{p}} \mathrm{O}_{2}$ and a small effect for improving performance. In a subgroup analysis, there was no statistically significant difference between 100 and $50 \mathrm{mg}$ sildenafil dose on $\mathrm{S}_{\mathrm{p}} \mathrm{O}_{2}$. Sildenafil had a moderate effect on increasing $\mathrm{S}_{\mathrm{p}} \mathrm{O}_{2}$ and performance at terrestrial hypobaric altitude but only a small effect on both in normobaric hypoxia. Regression analysis showed that hypoxic dose $\left(\mathrm{PO}_{2}\right)$ and metabolic rate do not account for a significant portion of the variance in effect size for sildenafil on PAP, $\mathrm{CO}, \mathrm{S}_{\mathrm{p}} \mathrm{O}_{2}$ and performance.

Conclusion This meta-analysis indicates that sildenafil reduces PAP, has a moderate to small effect on $\mathrm{CO}$ and $\mathrm{S}_{\mathrm{P}} \mathrm{O}_{2}$, and no effect on performance.

\section{INTRODUCTION}

The pulmonary vasculature is dynamic, dilating and constricting through a complex mechanism that regulates lung perfusion to optimise pulmonary blood pressure and gas exchange. Pulmonary artery smooth muscle relaxation occurs when nitric oxide (NO) diffuses from the vascular endothelium to smooth muscle cells where it increases the formation of cyclic guanosine $3^{\prime}, 5^{\prime}$ monophosphate (cGMP), which activates protein kinase G. This in turn decreases intracellular calcium concentrations, inhibiting the actin-myosin cross-bridge cycle, allowing the smooth muscle to relax. Phosphodiesterase-5 (PDE-5) is the main cGMP-hydrolysing enzyme. ${ }^{1}$ High levels of cGMP cause smooth

\section{Research summary}

What is already known?

- Several studies have examined the effect of sildenafil on reducing pulmonary artery pressure (PAP), increasing oxygen saturation $\left(\mathrm{S}_{\mathrm{P}} \mathrm{O}_{2}\right)$ and improving endurance performance with varied results.

- By reducing ventilation/perfusion mismatch, sildenafil may increase hypoxic maximum aerobic capacity by between $6 \%$ and $12 \%$.

What are the new findings?

- This meta-analysis found a large effect of sildenafil in increasing PAP, a moderate effect in increasing cardiac output and $\mathrm{S}_{\mathrm{p}} \mathrm{O}_{2}$, and no effect on performance.

- The type of hypoxia (normobaric vs hypobaric) and the level of hypoxia $\left(\mathrm{F}_{1} \mathrm{O}_{2}\right)$ do not alter the effects of sildenafil.

muscle cell relaxation while the presence of PDE-5 causes vasoconstriction. Sildenafil is a PDE-5 inhibitor with a molecular structure similar to cGMP. By occupying binding sites on PDE-5, sildenafil prevents cGMP breakdown, increasing the concentration available for pulmonary smooth muscle relaxation. ${ }^{2}$

Sildenafil, a medication primarily prescribed for erectile dysfunction, benefits patients with heart failure because of its limited hypotensive effect on the systemic circulation. Sildenafil produces small but physiologically insignificant reductions $(8 / 6 \mathrm{mmHg})$ in systemic blood pressure (BP) while supine ${ }^{3}$ and has a modest effect on systemic vascular resistance (maximum decrease of $16 \%){ }^{4}$ One important note is that participants with the greatest baseline $\mathrm{BP}$ show the greatest reductions in BP when using sildenafil. ${ }^{5}$ Because the decrease in $\mathrm{BP}$ is so small, there is no change in heart rate (HR) associated with therapeutic doses (40-100 mg) of sildenafil. ${ }^{4}$ Brachial artery diameter and flow-mediated dilatation, both estimates of endothelial function, are unaffected in healthy participants by $50 \mathrm{mg}$ of sildenafil. ${ }^{6}$ Sildenafil also appears to have very little impact on the coronary vasculature 
in healthy humans. Likewise, there is very little evidence that sildenafil has an inotropic effect in humans. ${ }^{47}$ There are no changes in cardiac output $(\mathrm{CO})$ or cardiac index associated with sildenafil and sildenafil does not change the force of cardiac contraction or cardiac performance in patients with stable ischaemic heart disease at rest. ${ }^{4}$ In one study of the sympathetic activity of sildenafil, BP and HR were unaffected, while muscle sympathetic nerve activity and plasma catecholamine levels increased, ${ }^{8}$ an indicator that sildenafil may be causing sympathetic activation independently of its haemodynamic effects.

Sildenafil is a highly selective PDE-5 inhibitor. ${ }^{3}$ The difference in its effect on the systemic vasculature described above and on the pulmonary vasculature is the result of PDE-5 distribution throughout the body. As PDE-5 is highly prevalent in the pulmonary arteries compared with the coronary and systemic circulation, ${ }^{79} 10$ a greater impact on pulmonary artery pressure (PAP) compared with systemic BP is expected..$^{10}$

In addition to its therapeutic use, sildenafil has been recently studied for its potential to enhance exercise performance, specifically in hypoxia. Athletes routinely compete at moderate altitudes 2000-4000 m) where they are exposed to decreased atmospheric pressure $\left(\mathrm{P}_{\text {atm }}\right)$. Decreases in the $\mathrm{PaO}_{2}$ of oxygen $\left(\mathrm{PO}_{2}\right)$ leads to decreased arterial $\mathrm{O}_{2}$ saturation $\left(\mathrm{SaO}_{9}\right)$ and a significant and variable decrement in performance. ${ }^{11}$ Low arterial $\mathrm{PO}_{2}$ triggers hypoxic pulmonary vasoconstriction (HPV) of the precapillary blood vessels resulting in increased $\mathrm{PAP}$ and decreased $\mathrm{CO}$ that may lead to further reductions in $\mathrm{SaO}_{2}$ and therefore performance. If the HPV response contributes to a loss in $\mathrm{SaO}_{2}$, reversing it pharmacologically may help to maintain $\mathrm{SaO}_{2}$ and reduce the decrement in endurance performance experienced at altitude.

Ghofrani et al were the first to report the effects of sildenafil on exercise performance in hypoxia. ${ }^{12}$ They found a significant improvement in exercise capacity and hypothesised that sildenafil improved hypoxic exercise tolerance by blunting the pulmonary hypertensive response, decreasing $\mathrm{PAP}$, and thereby reducing right ventricular afterload allowing an increase in CO. Since increases in mean power output during a time trial are directly related to performance outcomes, there is potential for sildenafil to be used as an ergogenic aid in endurance sport. Subsequent investigations of the effects of sildenafil on endurance performance in hypoxia using various doses of sildenafil, measures of endurance performance and fitness of participants have been inconsistent, with some showing a benefit ${ }^{12-14}$ and others showing no significant effect ${ }^{1516}$ when compared with placebo.

\section{Purpose}

We aimed to systematically review studies of the efficacy of sildenafil on exercise performance in hypoxia in healthy humans by meta-analysis. We also evaluated the effects of covariates in study methodology on sildenafil's effects on $\mathrm{PAP}, \mathrm{CO}, \mathrm{S}_{\mathrm{P}} \mathrm{O}_{2}$ and endurance performance.

\section{METHODS}

\section{Identification of studies}

A systematic literature review was carried out to identify original research investigating sildenafil use and exercise performance in hypoxia according to PRISMA guidelines and checklist. The online databases Medline (Ovid), PubMed and Web of Knowledge were searched up to August 2018. Keywords used in the search included (sildenafil) AND [(exercise) OR (performance)] AND [(hypoxia) OR (altitude)]. From each paper examined, references were manually reviewed for additional eligible research. Only peer-reviewed journal articles that reported original research using a randomised, placebo-controlled, cross-over design, on healthy human participants with sildenafil used in isolation and with a quantifiable measurement of exercise performance $\left(\mathrm{VO}_{2 \max }\right.$ test or time trial) were included. Studies without a measure of exercise performance were included if they had valuable haemodynamic measures ( $\mathrm{PAP}, \mathrm{CO}$ or $\mathrm{S}_{\mathrm{p}} \mathrm{O}_{2}$ ) that would contribute to the secondary analysis and met the remaining criteria. To ensure bias was minimised within the systematic review, we did not deviate from the defined inclusion criteria and thoroughly evaluated related research, including existing literature reviews. A funnel plot analysis was performed to determine the possibility of publication bias.

\section{Data extraction}

Outcomes assessed in the statistical analysis included measures of exercise performance, $\mathrm{CO}$ during rest and exercise, systolic PAP during rest and exercise, and estimates of $\mathrm{SaO}_{2}$ using pulse oximetry $\left(\mathrm{S}_{\mathrm{P}} \mathrm{O}_{2}\right)$ during rest and exercise. Exercise performance data were obtained in the form of peak power output during maximal exercise or mean power during fixed duration efforts or as peak oxygen uptake $\left(\mathrm{VO}_{o}\right)$ during exercise in hypoxia and normoxia. Mean, SD and sample size for each variable were extracted. When required, SD was calculated from $95 \%$ CIs using the equation $(\mathrm{SD}=\sqrt{\mathrm{n}} \times$ (upper limit-lower limit)/3.92). When median was reported, mean was estimated according to Hozo et al. ${ }^{17}$ If data were provided in a figure but not in numeric form, the authors were contacted and requested to provide values. If no response was received, figures were measured with a ruler to determine approximate values. If a study carried out repeated measures (eg, in multiple levels of hypoxia), only the most severe level of hypoxia was included in this meta-analysis as this would likely show the greatest effect of hypoxia and therefore, sildenafil. Hypoxic dose $\left(\mathrm{PO}_{2}\right)$ was calculated from atmospheric pressure $\left(\mathrm{P}_{\mathrm{atm}}\right)$ and reported as fraction of inspired $\mathrm{O}_{2}\left(\mathrm{~F}_{\mathrm{I}} \mathrm{O}_{2}\right) \cdot{ }^{18}$ If $\mathrm{P}_{\text {atm }}$ was not reported and the study took place at sea level, 760 $\mathrm{mm} \mathrm{Hg}$ was used. Percentage of $\mathrm{VO}_{2 \max }$ was determined by calculating the fraction of maximum power output (W) that was maintained during submaximal exercise. If power output was not reported, $\mathrm{VO}_{2}$ data were substituted. If $\mathrm{VO}_{2}$ was not reported, age was used to calculate predicted maximum HR that was compared with test HR. 


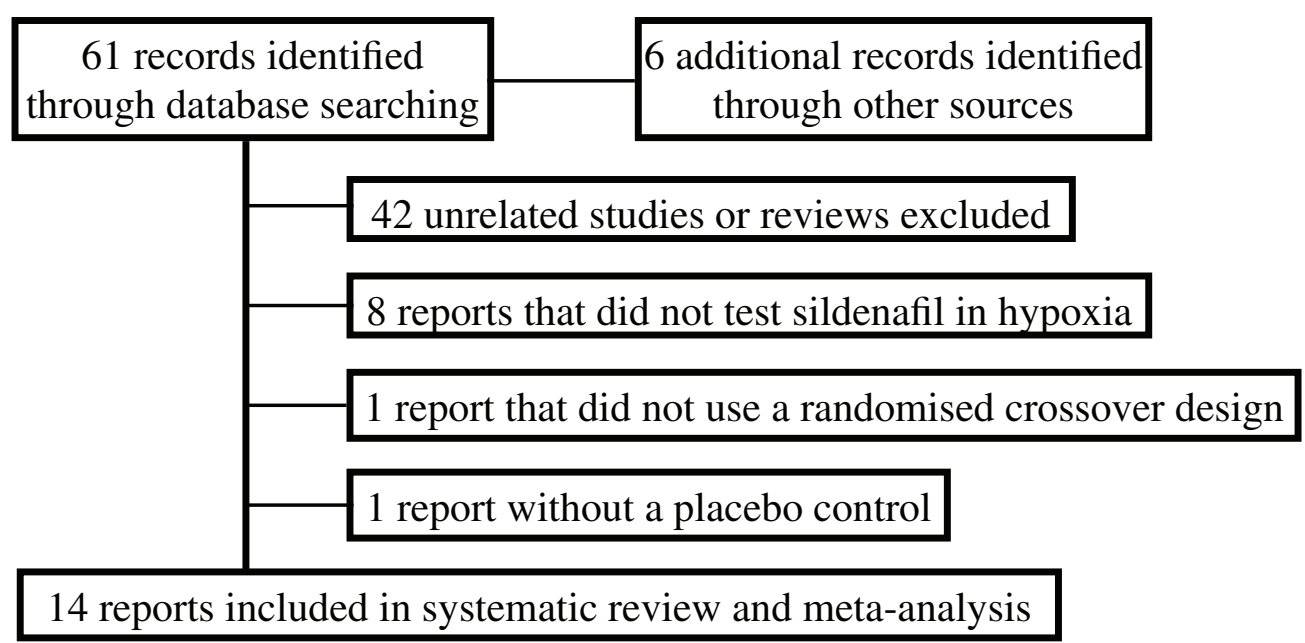

Figure 1 PRISMA diagram for meta-analysis.

Data are presented in this analysis in the form of mean $( \pm \mathrm{SD})$.

\section{Analyses}

The standardised mean difference between placebo and sildenafil were determined with 95\% CI using Comprehensive Meta-Analysis Software (Biostat, Englewood, New Jersey, USA). Given the small sample size $(n<20)$ of all but one study (Jacobs et al, n=35), ${ }^{16}$ Hedges' g was selected as the measure of effect size ${ }^{19}$ using the random-effects model (chosen because each study represents a unique sample population), with interpretations of magnitude set at small $(>0.2)$, moderate $(>0.5)$ and large $(>0.8) .{ }^{20}$ The $\mathrm{I}^{2}$ measure of inconsistency was used to assess between-study variability. ${ }^{21}$ We chose values $<30 \%$ to represent low heterogeneity, values from $30 \%$ to $60 \%$ to represent moderate heterogeneity and values $>60 \%$ to represent high heterogeneity. Subgroup analysis was performed based on the exertion level: rest and exercise, the type of hypoxia: normobaric $(\mathrm{NH})$ and hypobaric $(\mathrm{HH})$, and sildenafil dose administered in each study: 50 $\mathrm{mg}$ and $100 \mathrm{mg}$. Meta-regression analysis was completed using test hypoxic dose and metabolic rate (percentage of maximal capacity) as variables.

\section{RESULTS}

\section{Descriptive data}

Sixteen studies of sildenafil use in hypoxia were originally identified (figure 1). Of these, two were excluded due to a lack of placebo control, ${ }^{22}$ or randomised cross-over design. ${ }^{23}$ The remaining 14 studies included 210 total participants (157 male, 53 female), shown in online supplementary table 1 (web appendix). Of these, four studies were included that had a measure of $\mathrm{S}_{\mathrm{P}} \mathrm{O}_{2}$ or PAP but not a performance variable $(\mathrm{n}=42) .{ }^{24-27}$ All studies used a randomised cross-over design with a placebo and at least one sildenafil condition. Each data set was analysed separately. Each study recruited 'trained' participants; however, only nine studies reported $\mathrm{VO}_{2 \max }$ values at sea level. Mean fitness levels ranged from $36.0( \pm 6.0) \mathrm{mL} \mathrm{kg}^{-1} \mathrm{~min}^{-128}$ to $68.6( \pm 8.0)$ $\mathrm{mL} \mathrm{kg}{ }^{-1} \min ^{-1}$. $^{11}$

More than half of the research was conducted in $\mathrm{NH}$, that is, manipulating $\mathrm{F}_{\mathrm{I}} \mathrm{O}_{2}$ at a constant $\mathrm{P}_{\text {atm }}$. Only three studies used $\mathrm{HH}$ exposures ${ }^{13} 2429$ where $\mathrm{F}_{\mathrm{I}} \mathrm{O}_{2}$ is kept constant and $\mathrm{P}_{\text {atm }}$ is reduced. One study used two levels of $\mathrm{NH}$ : moderate $\left(\mathrm{MH}, \mathrm{F}_{\mathrm{I}} \mathrm{O}_{2}=0.162\right)$ and severe $(\mathrm{SH}$, $\left.\mathrm{F}_{\mathrm{I}} \mathrm{O}_{2}=0.128\right)^{1}$ though only the latter was included in our analysis. Sildenafil was administered in a $50 \mathrm{mg}$ dose in all studies except two that used a $40 \mathrm{mg}$ dose $^{1326}$ and three that administered $100 \mathrm{mg} .{ }^{2425} 30$ Fourteen studies examined the effect of acute supplementation with prescription of sildenafil ranging from 30 to $120 \mathrm{~min}$ before exercise. The remaining study, by Richalet $e t a l$, used a 2-day supplementation protocol with $40 \mathrm{mg}$ doses taken three times daily. ${ }^{13}$ Funnel plot analysis shows a potential asymmetry, suggesting the existing literature surrounding sildenafil and performance in hypoxia may be missing non-significant studies (figure 2).

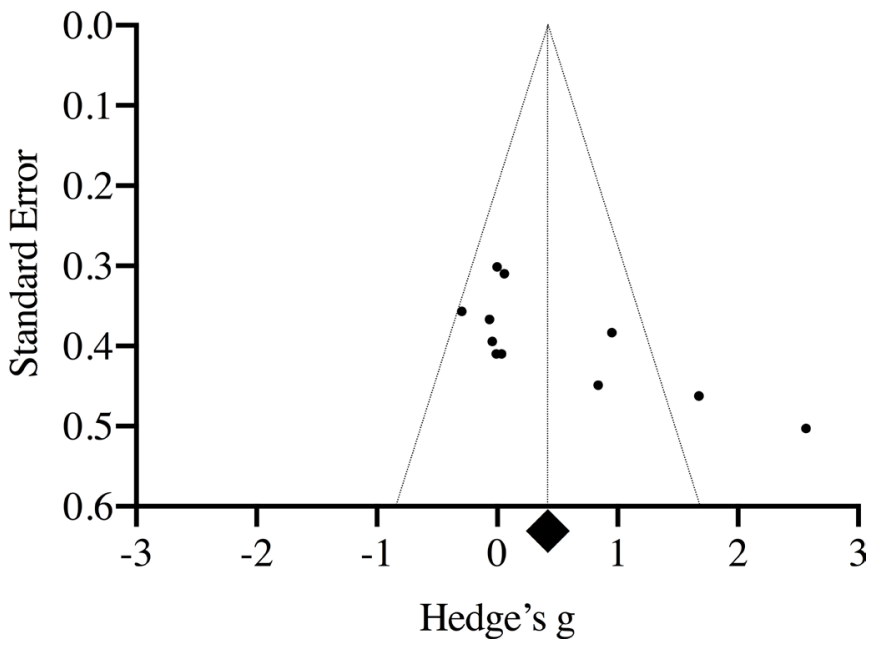

Figure 2 Funnel plot for publication bias. 
Study and Year

\begin{tabular}{|c|c|}
\hline Ghofrani 2004 & $-1.52(-2.34--0.70)$ \\
\hline Ricart 2005 & $-1.80(-2.58--1.01)$ \\
\hline Richalet 2005 & $-1.64(-2.54--0.74)$ \\
\hline Snyder 2008 & $0.11(-0.61-0.827)$ \\
\hline Exercise Pooled & $-1.19(-2.13--0.26)$ \\
\hline Faoro 2007 & $-0.78(-1.53--0.03)$ \\
\hline Zhao 2001 & $-1.25(-2.17--0.33)$ \\
\hline Ghofrani 2004 & $-3.54(-4.71--2.36)$ \\
\hline Ricart 2005 & $-2.09(-2.91--1.26)$ \\
\hline Reichenberger 2007 & $-0.86(-1.61--0.10)$ \\
\hline Snyder 2008 & $-1.07(-1.85--0.30)$ \\
\hline Rest Pooled & $-1.52(-2.23--0.82)$ \\
\hline
\end{tabular}

Figure 3 Pulmonary artery pressure forest plot.

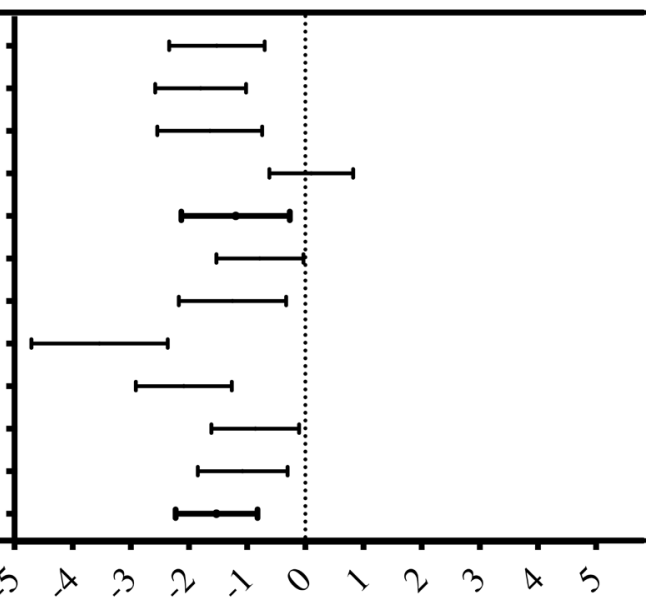

Favours Sildenafil Favours Control

\section{Pulmonary artery pressure}

PAP was evaluated in seven studies (figure 3) using the tricuspid jet method with six datasets at rest ${ }^{12} 1524252728$ and four during exercise. ${ }^{12} 132428$

At rest, the pooled corrected effect size was -1.523 ( $95 \%$ CI -0.818 to -2.229$)$ indicating a large effect in favour of sildenafil over placebo in reducing PAP with six of six trials reporting significantly decreased PAP at rest $(\mathrm{p}<0.05)$ and an $\mathrm{I}^{2}$ value of $76.0 \%(\mathrm{n}=83)$.

For studies of exercising PAP, $\mathrm{I}^{2}$ was $81.5 \% \quad(\mathrm{n}=57)$. The pooled corrected effect size was $-1.195(-0.262$ to -2.128) indicating a large effect in favour of sildenafil over placebo with three of four trials reporting significantly decreased PAP during exercise despite high heterogeneity.

\section{Cardiac Output}

CO was evaluated in nine studies with a total of 16 datasets (figure 4) using several different methods including impedance, ${ }^{1}{ }_{13} \quad 14 \quad 16$ nitrous oxide gas rebreathing, ${ }^{12} 28$ fingertip $\mathrm{BP}$ waveform analysis ${ }^{30}$ and echocardiography. ${ }^{11}{ }^{15}$ Seven resting trials and nine exercise trials were included in the analysis.

For studies of resting $\mathrm{CO}, \mathrm{I}^{2}$ was $65.3 \%(\mathrm{n}=95)$. The pooled corrected effect size was 0.551 (0.059 to 1.042) indicating a moderate effect in favour of sildenafil over placebo with three of seven datasets reporting significantly increased $\mathrm{CO}$ at rest $(\mathrm{p}<0.05)$.

For studies of exercising CO, $\mathrm{I}^{2}$ was $29.4 \% \quad(\mathrm{n}=126)$. The pooled corrected effect size during exercise was 0.303 (0.011 to 0.595$)$ indicating a small effect in favour

\begin{tabular}{|c|c|c|c|}
\hline Study and Year & Hed & 's G (95\% CI) & Hedge's G (95\% CI) \\
\hline Ghofrani 2004 & 1.41 & $(0.60-2.22)$ & $\longmapsto$ \\
\hline Kressler 2011 & 0.34 & $(-0.29-0.96)$ & $\longrightarrow$ \\
\hline Toro 2015 & 0.18 & $(-0.60-0.95)$ & $\longrightarrow$ \\
\hline Richalet 2005 & -0.05 & $(-0.83-0.72)$ & $\longrightarrow$ \\
\hline Snyder 2008 & -0.31 & $(-1.03-0.41)$ & 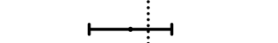 \\
\hline Jacobs (women) 2011 & 0.22 & $(-0.48-0.92)$ & $\stackrel{\vdots}{\longmapsto}$ \\
\hline Jacobs (men) 2011 & 0.22 & $(-0.39-0.83)$ & - \\
\hline Carter 2019 & 0.47 & $(-0.38-1.32)$ & \\
\hline Hsu 2006 & 0.46 & $(-0.39-1.32)$ & \\
\hline Exercise Pooled & 0.30 & $(0.01-0.59)$ & \\
\hline Kressler 2011 & 0.20 & $(-0.43-0.82)$ & \\
\hline Snyder 2008 & 0.48 & $(-0.24-1.22)$ & \\
\hline Hsu 2006 & 0.66 & $(-0.20-1.52)$ & \\
\hline Ghofrani 2004 & 1.52 & $(0.70-2.35)$ & \\
\hline Faoro 2007 & 1.39 & $(0.58-2.19)$ & \\
\hline Toro 2015 & 0.06 & $(-0.71-0.83)$ & \\
\hline Richalet 2005 & -0.34 & $(-1.11-0.44)$ & \\
\hline Rest Pooled & 0.55 & $(0.06-1.04)$ & 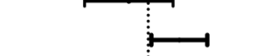 \\
\hline
\end{tabular}

Figure 4 Cardiac output forest plot. 


\begin{tabular}{|c|c|c|}
\hline Study and Year & Hedge's G (95\% CI) & Hedge's G (95\% CI) \\
\hline Zhao 2001 & $2.55 \quad(-0.59-1.10)$ & -1 \\
\hline Reichenberger 2007 & $(-0.67-0.77)$ & $\longmapsto$ \\
\hline Snyder 2008 & $0.31 \quad(-0.42-1.03)$ & \\
\hline Ricart 2005 & $(-0.36-0.96)$ & -1 \\
\hline Lalande 2009 & $0.09 \quad(-0.60-0.79)$ & \\
\hline Kressler 2011 & $(-0.15-1.05)$ & \\
\hline Jacobs (women) 2011 & $(-0.45-0.95)$ & \\
\hline Jacobs (men) 2011 & $(-0.39-0.83)$ & \\
\hline Hsu 2006 & $(-0.11-1.64)$ & \\
\hline Faoro 2007 & $(0.27-1.81)$ & \\
\hline Ghofrani 2004 & $(1.59-3.56)$ & \\
\hline Carter 2019 & $(-0.47-1.31)$ & \\
\hline NH Pooled & $0.50 \quad(0.19-0.82)$ & $\mapsto$ \\
\hline Toro 2015 & $(-0.26-1.31)$ & \\
\hline Rodway 2016 & $(-0.64-0.90)$ & $\longmapsto$ \\
\hline Richalet 2005 & $(-0.27-1.30)$ & \\
\hline HH Pooled & $0.39 \quad(-0.06-0.84)$ & : \\
\hline$S_{p} O_{2}$ Pooled & $0.46 \quad(0.20-0.72)$ & $\mapsto$ \\
\hline
\end{tabular}

Favours Control Favours Sildenafil

Figure 5 Oxygen saturation forest plot. $\mathrm{HH}$, hypobaric hypoxia; $\mathrm{NH}$, normobaric hypoxia; $\mathrm{S}_{\mathrm{p}} \mathrm{O}_{2}$, oxygen saturation.

of sildenafil over placebo with only two of nine datasets reporting significantly increased $\mathrm{CO}$ during exercise $(\mathrm{p}<0.05)$.

\section{Oxygen saturation}

Oxygen saturation was measured using pulse oximetry in 14 studies either during exercise or rest (figure 5). Three datasets were from studies conducted at altitude $(\mathrm{n}=36)$ and 12 datasets were from studies conducted in $\mathrm{NH}$ $(\mathrm{n}=189)$. In all trials $(\mathrm{n}=225), \mathrm{I}^{2}$ was $43.7 \%$. The pooled corrected effect size was 0.47 (0.22 to 0.73$)$ indicating a moderate effect in favour of sildenafil over placebo.

\section{Performance}

Exercise performance (figure 6) was evaluated in 10 studies using either maximal exercise tests or time trials. The performance metric measured in each study is listed in (online supplementary table 1 (web appendix). All trials were conducted on an upright bicycle ergometer except for one that used a semi-supine (recumbent)

\section{Study and Year $\quad$ Hedge's G (95\% CI) Hedge's G (95\% CI)}

\begin{tabular}{|c|c|c|}
\hline Ghofrani 2004 & $2.58(1.59-3.57)$ & $\longmapsto$ \\
\hline Hsu 2006 & $0.84(-0.04-1.72)$ & $\longrightarrow$ \\
\hline Faoro 2007 & $-0.06(-0.78-0.66)$ & ю \\
\hline Snyder 2008 & $0.97(0.21-1.73)$ & $\longmapsto$ \\
\hline Kressler 2011 & $0.00 \quad(-0.59-0.59)$ & • \\
\hline Jacobs (women) 2011 & $-0.29(-0.99-0.41)$ & 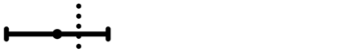 \\
\hline Jacobs (men) 2011 & $0.06(-0.55-0.67)$ & $\stackrel{\vdots}{\longmapsto}$ \\
\hline Carter 2019 & $0.00 \quad(-0.80-0.80)$ & ط \\
\hline NH Pooled & $0.46(-0.09-1.00)$ & $\rightarrow$ \\
\hline Richalet 2005 & $1.68(0.78-2.59)$ & $\longmapsto$ \\
\hline Toro 2015 & $0.02(-0.78-0.83)$ & • \\
\hline Rodway 2016 & $-0.04(-0.81-0.73)$ & ط \\
\hline HH Pooled & $0.53(-0.52-1.59)$ & 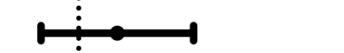 \\
\hline Performance Pooled & $0.47 \quad(0.01-0.94)$ & 正 \\
\hline
\end{tabular}

Favours Control Favours Sildenafil

Figure 6 Performance forest plot. $\mathrm{HH}$, hypobaric hypoxia; $\mathrm{NH}$, normobaric hypoxia. 
position. ${ }^{12}$ Three trials were conducted at altitude $(\mathrm{n}=35)$ and five were conducted in $\mathrm{NH}(\mathrm{n}=119)$. In all trials $(n=154), I^{2}$ was $75.4 \%$. The pooled corrected effect size was 0.474 (0.012 to 0.936$)$ indicating a small effect in favour of sildenafil over placebo.

\section{Subgroup analysis}

Subgroup analyses were completed to evaluate the sensitivity to the dose of sildenafil and the type of hypoxic exposure. The most common dose of sildenafil used was $50 \mathrm{mg}$ followed by $100 \mathrm{mg}$. Alternative doses are shown in online supplementary table 1 (web appendix) . Type of hypoxic exposure was classified as $\mathrm{NH}$ or $\mathrm{HH}$ for the $\mathrm{S}_{\mathrm{P}} \mathrm{O}_{2}$ and performance datasets (also shown in online supplementary table 1 web appendix).

The only dataset with four or more sildenafil dose data points was $\mathrm{S}_{\mathrm{P}} \mathrm{O}_{2}$ and the pooled corrected effect size for the $100 \mathrm{mg}$ dose group was 0.343 (95\% CI 0.715 to -0.029 ) indicating no effect in favour of sildenafil or placebo with zero of four datasets reporting significantly increased $\mathrm{S}_{\mathrm{P}} \mathrm{O}_{2}$. The pooled corrected effect size for the $50 \mathrm{mg}$ dose was 0.525 (95\% CI 0.772 to 0.278 ), indicating a small effect in favour of sildenafil but one that was not statistically different from the $100 \mathrm{mg}$ dose with only two ${ }^{1215}$ of nine datasets reporting significantly increased $\mathrm{S}_{\mathrm{p}} \mathrm{O}_{2}$.

For studies of $\mathrm{S}_{\mathrm{P}} \mathrm{O}_{2}$ at actual altitude (figure 5), the pooled corrected effect size was 0.380 (95\% CI 0.126 to 0.635 ) indicating a small effect in favour of sildenafil over placebo with zero of three trials reporting significantly increased $\mathrm{S}_{\mathrm{P}} \mathrm{O}_{2}(\mathrm{p}<0.05)$. For studies of $\mathrm{S}_{\mathrm{P}} \mathrm{O}_{2}$ in $\mathrm{NH}$, the pooled corrected effect size was 0.50 (95\% CI 0.19 to 0.82 ) indicating a moderate effect in favour of sildenafil over placebo with only two ${ }^{12} 15$ of 12 datasets reporting significantly increased performance $(\mathrm{p}<0.05)$.

For studies of performance at altitude (figure 6), the pooled corrected effect size was 0.533 (95\% CI -0.520 to 1.585 ) indicating a moderate effect in favour of sildenafil over placebo with one ${ }^{13}$ of three trials reporting significantly increased performance $(\mathrm{p}<0.05)$. For studies of performance in $\mathrm{NH}$, pooled corrected effect size was 0.457 (95\% CI -0.090 to 1.004$)$ indicating a small effect in favour of sildenafil over placebo with two ${ }^{12} 28$ of eight datasets reporting significantly increased performance $(\mathrm{p}<0.05)$.

\section{Regression analysis}

The hypoxic dose $\left(\mathrm{PO}_{\mathrm{o}}\right)$ for every study was calculated from reported $\mathrm{F}_{\mathrm{I}} \mathrm{O}_{2}, \mathrm{~PB}$ and study altitude. For studies during exercise, the metabolic rate (\% maximum) was determined. Both variables online supplementary table 1 (web appendix) were included in meta-regression to account for variance in each dataset (PAP, $\mathrm{CO}, \mathrm{S}_{\mathrm{P}} \mathrm{O}_{2}$ and performance). The $\mathrm{p}$ value for each covariate in each dataset is $>0.05$, indicating these covariates do not explain a significant portion of the variance in effect size.

\section{Adverse events}

Two studies reported minor headache in three participants. ${ }^{12}{ }^{24}$ Kressler et al measured headache scores in all participants (using the Lake Louise Score) and found that participants who used sildenafil had slightly but not significantly higher headache scores. ${ }^{1}$ One subject reported flushing of the skin and no subjects reported any erectile response. ${ }^{24}$

\section{DISCUSSION}

In our meta-analysis of the efficacy of sildenafil in decreasing PAP to increase $\mathrm{CO}$, and thereby $\mathrm{S}_{\mathrm{P}} \mathrm{O}_{2}$ and exercise performance, we found that sildenafil has a large effect in reducing PAP at rest and during exercise in otherwise healthy humans at altitude. From our analysis of the pooled data, this effect on PAP leads to a moderate increase in $\mathrm{CO}$ at rest and a small increase in $\mathrm{CO}$ during exercise, driven primarily by one study with a significant increase. A reduction of $\mathrm{SaO}_{2}$ is believed to be one of the primary determinants of the decrement in maximal exercise performance in hypoxia. ${ }^{31}$ Several studies have associated a reduction in $\mathrm{S}_{\mathrm{P}} \mathrm{O}_{2}$ with the decrement in maximal exercise performance. ${ }^{31}$ Our pooled results showed a moderate increase in $\mathrm{S}_{\mathrm{P}} \mathrm{O}_{2}$ with sildenafil driven by only two studies ${ }^{1215}$ that showed significant increases. There was only a small effect of sildenafil in increasing performance. Our results indicate that as we successively examine the expected mechanisms of action of sildenafil on PAP, CO, $\mathrm{S}_{\mathrm{P}} \mathrm{O}_{2}$ and finally performance, the effect size is reduced at each step. This finding indicates that the contribution to the decrement in performance at altitude from hypoxic pulmonary vasoconstriction (and the improvement in performance from sildenafil) is likely small. In addition to examining the overall effect of sildenafil and its effect on several variables that impact performance, we examined several methodological factors that might modulate the effectiveness of sildenafil on our outcome variables including sildenafil dose, type of hypoxic exposure, hypoxic dose and metabolic rate.

\section{Subgroup analysis}

Sildenafil was delivered orally in all studies ranging in dose from $40 \mathrm{mg}$ to $100 \mathrm{mg}$ acutely. It is unlikely that differences in effect size are due to dosage as the inhibitory concentration $\left(\mathrm{IC}_{50}=3.5 \mathrm{nM}\right)$ of sildenafil is very low, meaning a small dose is sufficient to significantly inhibit PDE-5. ${ }^{3}$ It is unknown if a multiday (chronic) dosing strategy is more efficacious compared with an acute dose for improving exercise performance. Only one study employed a full day loading protocol (three doses of $40 \mathrm{mg}$ sildenafil over 24 hours before testing). ${ }^{13}$ The remainder of the studies in this analysis used an acute dose of either $50 \mathrm{mg}$ or $100 \mathrm{mg}$ and were included in a subgroup analysis of the $\mathrm{S}_{\mathrm{P}} \mathrm{O}_{2}$ dataset that showed no significant difference between the two doses. This finding supports the conclusion that a supratherapeutic dose does not increase the likelihood of a benefit in $\mathrm{S}_{\mathrm{P}} \mathrm{O}_{2}$ and therefore performance. A study examining 
the difference between acute and chronic dosing procedures, specifically in healthy exercising humans, may be useful to determine the effect of each on exercise performance. Serum cGMP was measured in only two studies. Snyder found that cGMP was significantly higher in the group treated with sildenafil ${ }^{28}$ while Richalet found that cGMP was non-significantly higher in the group treated with sildenafil at the timepoint (day 1) from which data were included in this analysis. ${ }^{13}$ Zhao et al did measure cGMP in murine participants in their study and found it significantly increased by sildenafil but did not measure cGMP in the human participants. Improved measures of the effect of sildenafil on PDE-5 inhibition would strengthen future research.

We looked at the effect of hypoxia on the outcome variables in two ways, first by examining the difference in the type of hypoxic exposure. The difference in the physiological response between equivalent $\mathrm{P}_{\mathrm{A}} \mathrm{O}_{2}$ at differing $\mathrm{P}_{\mathrm{B}}$ $(\mathrm{NH}$ and $\mathrm{HH})$ is a highly contentious one. ${ }^{32}$ The primary difference between $\mathrm{NH}$ and $\mathrm{HH}$ has been attributed to the density of air, which is lower in $\mathrm{HH}$ exposures, and may account for small differences in breathing frequency, dead space ventilation and total ventilation. ${ }^{32}$ The majority of the studies included in our research were carried out in $\mathrm{NH}$; only three studies in the $\mathrm{S}_{\mathrm{P}} \mathrm{O}_{2}$ and performance datasets used HH. ${ }^{13} 2930$ There was no significant difference between the $\mathrm{HH}$ and $\mathrm{NH}$ pooled effect sizes on either $\mathrm{S}_{\mathrm{P}} \mathrm{O}_{2}$ or performance indicating that the type of hypoxic exposure does not impact the effect of sildenafil on these variables. This finding is consistent with the mechanism of action of sildenafil, which should reduce PAP and not affect ventilatory responses.

Hypoxic dose varied between datasets attempting to simulate a variety of different altitudes. Studies in terrestrial altitude ranged from $2 \mathrm{~m}$ above sea level (control condition) to $5245 \mathrm{~m}$. The fraction of inspired $\mathrm{O}_{2}$ ranged from 0.21 to 0.10 . When the equivalent altitude $\mathrm{PO}_{2}$ was calculated, dose ranged from 104 to $70 \mathrm{~mm} \mathrm{Hg}$ which represents an approximate range in simulated altitude from 2750 to $5500 \mathrm{~m}$ online supplementary table 1 (web appendix). Using meta-regression techniques in each dataset (PAP, $\mathrm{CO}, \mathrm{S}_{\mathrm{P}} \mathrm{O}_{2}$ and performance), we determined that differences in study $\mathrm{PO}_{2}$ (true or simulated altitude) did not account for variance in the outcome variables with sildenafil use. Further research at varying $\mathrm{PO}_{2}$ is necessary, however, because of the methodological heterogeneity described above.

It has been hypothesised that a threshold altitude may limit the usefulness of sildenafil at lower altitudes while allowing greater benefits above. ${ }^{1}$ Only one study examined the effect of sildenafil during exercise in moderate $\mathrm{NH}\left(\sim 2100 \mathrm{~m}, 0.162 \quad \mathrm{~F}_{\mathrm{I}} \mathrm{O}_{2}\right) .{ }^{1}$ The results closely match those of the non-responders in the study by Hsu et al and no improvement in performance was found. A longer (15 $\mathrm{km}$ ) time trial was used to maximise the aerobic component of exercise. The authors concluded that below 3000 $\mathrm{m}$, the HPV response does not increase $\mathrm{CO}$ enough for sildenafil to cause a recognisable improvement in performance and $\mathrm{CaO}_{2}$ is the primary limiting factor of performance. Unfortunately, because of the measurement technique used in the study, $\mathrm{CO}$ was measured in only 8 of 21 participants. Only one study was included at a $\mathrm{PO}_{2}$ equivalent to less than $3000 \mathrm{~m},{ }^{29}$ so our meta-regression does not test the existence of a threshold altitude below that limit. While it may be true that sildenafil is unlikely to be effective at improving endurance performance below $3000 \mathrm{~m}$, it is more likely a continuum with very few participants who have a significant HPV response below that altitude who would then benefit from the effects of sildenafil.

The studies of exercise performance all used maximal exercise tests or time trials as their primary outcome while studies of PAP, $\mathrm{CO}$ and $\mathrm{S}_{\mathrm{P}} \mathrm{O}_{2}$ used a mix of maximal and submaximal exercise. Maximal test protocol was described by Ghofrani $e t a l^{2}$ as a stepwise increase in power with participants cycling to volitional exhaustion. Results were reported as power output $\left(\right.$ at $\left.\mathrm{VO}_{2 \max }\right)$ in watts except by Richalet $e t a l$, who reported the percentage decrease in $\mathrm{VO}_{2 \max }$ compared with normoxia. ${ }^{13}$ For time trial studies, power was reported in mean wattage. Time trials varied in distance from $6 \mathrm{~km}$ to $16.1 \mathrm{~km}$ online supplementary table 1 (web appendix). Our meta-regression analysis showed that metabolic rate (as a percentage of maximum) did not account for the variance in the outcome variables with sildenafil use. While metabolic rate would have a significant impact on the absolute values for PAP, $\mathrm{CO}$ and $\mathrm{S}_{\mathrm{P}} \mathrm{O}_{2}$, the effect of sildenafil on the variables was unaffected. In these exercise protocols, significantly different energy systems are used and metabolic variations could account for the differences in results, especially in trained athletes. It is possible that during submaximal exercise, a buffer may remain for sildenafil to increase $\mathrm{CO}$ while during maximal exercise, there is no additional capacity, so performance remains compromised.

\section{Additional influencing factors}

To complete our analysis, we considered several other factors that might modulate the effectiveness of sildenafil including the possibility of responders and non-responders, the influence of central regulation on exercise, and outlier studies. These concepts were not included in the statistical analysis but deserve mention.

Our results indicate that sildenafil is an effective pulmonary vasodilator in hypoxia that may increase $\mathrm{CO}$ but may not have a significant effect on overall performance outcomes in all athletes. Of particular interest is the 2006 study by Hsu et al. Several of the participants showed a significant improvement in time trial performance following sildenafil administration. These participants also showed an exaggerated decline in exercise performance in hypoxia. ${ }^{14}$ By grouping their participants according to those with a greater than or less than 1 min improvement in time trial performance between placebo and sildenafil, the authors classified participants as responders and non-responders. The responders 
had higher pulmonary vascular resistance (PVR) due to increased PAP and resultant increased RV afterload. In these participants, sildenafil improved performance by decreasing PAP and PVR, reducing RV afterload and improving V/Q mismatch. Non-responders had no such increases in PAP, PVR or performance after taking sildenafil. The authors also noted that the responders appeared to have a slightly (but not significantly) higher aerobic fitness level than non-responders. Criticisms of the study include the small sample size and the time trial distance $(6 \mathrm{~km})$. Kressler et al believe that a $6 \mathrm{~km}$ time trial may be too short with a minimal aerobic component such that it is not possible to detect performance improvements with sildenafil. ${ }^{1}$ These criticisms were supported by a study from the same research group as the Kressler paper, with a much larger sample size $(n=35)$ and found no significant improvement in performance with sildenafil using a similar $6 \mathrm{~km}$ time trial protocol. ${ }^{16}$ Kressler acknowledges that responders (as described by Hsu) may represent only a small fraction of the population and may not have been included in the larger study. ${ }^{1}$ An attempt by Carter et al to compare the effect of sildenafil on performance with the decrement in performance caused by hypoxia found no correlation. ${ }^{11}$ No other study has sought to determine the existence of responders and non-responders while several showed no effect of sildenafil in all participants. It is possible that significant differences in methods related to sample population or exercise type may affect the outcome of the experiments, especially noticeable when dealing with the small margins that constitute differences in athletic performance at a high level. The potential for sildenafil responders requires further research with an emphasis on minimising methodological differences, perhaps by screening for participants with higher than normal pulmonary vascular resistance and increased PAP. Similarly, many of the studies included in this analysis included both male and female participants but no studies specifically examined any sex differences in response to sildenafil; this is an area that merits future research.

In individuals with increased PAP, determinants of performance, such as efferent commands to the heart and muscle, may be restricted by central mechanisms to protect the brain from hypoxia. If the athlete were to further increase $\mathrm{CO}$, transit time might be reduced sufficiently to reduce $\mathrm{SaO}_{2}$ to the point that brain oxygenation is negatively affected. If the brain is centrally regulating exercise output in hypoxia, this might represent a protective mechanism that is circumvented by using sildenafil as an ergogenic substance. For this reason, future research should also consider the relationship between changes in performance in hypoxia and $\mathrm{SaO}_{2}$ and not just examine PAP.

Throughout our analysis, one study stood out as showing a strong effect of sildenafil on each outcome without any major methodological heterogeneity. ${ }^{12}$ Without the study by Ghofrani et al, the pooled effect of sildenafil on $\mathrm{S}_{\mathrm{P}} \mathrm{O}_{2}$ and $\mathrm{CO}$ would be low. This study also contributed to the moderate to high $\mathrm{I}^{2}$ values. We believe it is important to note this as an outlying data point, and that its effect on the conclusion should be considered carefully. The potential lack of published negative studies would further skew the pooled effect towards a positive effect of sildenafil.

\section{Limitations}

Questions surrounding methodology remain; however, none of the studies we identified examine the relationship between increased PAP and decreased exercise performance in hypoxia or evaluated the effectiveness of sildenafil directly on the individual decrement in performance in hypoxia. Oxygenation is often unmeasured or left out from analysis despite being an important determinant of performance in hypoxia.

\section{CONCLUSION}

Sildenafil was investigated as an ergogenic substance during endurance exercise in hypoxia because it is believed that reductions in PAP will allow increases in $\mathrm{CO}$ and therefore exercise capacity through a reduction of right ventricular afterload. This meta-analysis reveals that while sildenafil is effective in reducing PAP, it has a moderate to small effect on $\mathrm{CO}$ and $\mathrm{S}_{\mathrm{P}} \mathrm{O}_{2}$ and does not reliably affect performance. We can neither rule out a trivial, or truly nil, effect of sildenafil on performance. Thus, while PAP is moderately reduced due to sildenafil, other factors appear to be involved in regulation of exercise performance as well.

Future research must focus on (1) the mechanism through which HPV contributes to the decrement in exercise performance and (2) the relationship between decreased exercise capacity in hypoxia and increased capacity after sildenafil administration. Future studies should measure blood oxygenation, by ensuring pulse oximeter readings are reliable, or via arterial blood gas measurements, as well as consider monitoring muscle oxygenation so that investigators begin to understand all the factors that contribute to hypoxic exercise.

Acknowledgements The authors wish to thank Dr William K Milsom for his contribution to the conception of this meta-analysis as well as his input on the manuscript.

Contributors EAC was responsible for conception of the meta-analysis, data collection, statistical analysis and preparation of the manuscript. KL assisted with conception of the meta-analysis, statistical analysis and manuscript preparation. WS assisted with conception of the meta-analysis and manuscript preparation. MK assisted with conception of the meta-analysis, statistical analysis and manuscript preparation. All coauthors have reviewed and approved the manuscript.

Funding The authors have not declared a specific grant for this research from any funding agency in the public, commercial or not-for-profit sectors.

Competing interests None declared.

Patient consent for publication Not required.

Provenance and peer review Not commissioned; internally peer reviewed.

Open access This is an open access article distributed in accordance with the Creative Commons Attribution Non Commercial (CC BY-NC 4.0) license, which permits others to distribute, remix, adapt, build upon this work non-commercially, and license their derivative works on different terms, provided the original work is 
properly cited, appropriate credit is given, any changes made indicated, and the use is non-commercial. See: http://creativecommons.org/licenses/by-nc/4.0/.

\section{REFERENCES}

1. Kressler J, Stoutenberg M, Roos BA, et al. Sildenafil does not improve steady state cardiovascular hemodynamics, peak power, or 15-km time trial cycling performance at simulated moderate or high altitudes in men and women. Eur J Appl Physiol 2011;111:3031-40.

2. Barnett CF, Machado RF. Sildenafil in the treatment of pulmonary hypertension. Vasc Health Risk Manag 2006;2:411-22.

3. Gillies HC, Roblin D, Jackson G. Coronary and systemic hemodynamic effects of sildenafil citrate: from basic science to clinical studies in patients with cardiovascular disease. Int J Cardiol 2002;86:131-41.

4. Jackson G, Benjamin N, Jackson N, et al. Effects of sildenafil citrate on human hemodynamics. Am J Cardiol 1999;83:13-20.

5. Jackson G, Montorsi P, Cheitlin MD. Cardiovascular safety of sildenafil citrate (Viagra): an updated perspective. Urology 2006;68(3 Suppl):47-60.

6. Dishy V, Sofowora G, Harris PA, et al. The effect of sildenafil on nitric oxide-mediated vasodilation in healthy men. Clin Pharmacol Ther 2001;70:270-9.

7. Wallis RM, Corbin JD, Francis $\mathrm{SH}$, et al. Tissue distribution of phosphodiesterase families and the effects of sildenafil on tissue cyclic nucleotides, platelet function, and the contractile responses of trabeculae carneae and aortic rings in vitro. Am J Cardiol 1999;83:3-12

8. Phillips BG, Kato M, Pesek CA, et al. Sympathetic activation by sildenafil. Circulation 2000;102:3068-73.

9. Rabe KF, Tenor H, Dent G, et al. Identification of PDE isozymes in human pulmonary artery and effect of selective PDE inhibitors. Am J Physiol 1994;266:L536-L543.

10. Corbin JD, Beasley A, Blount MA, et al. High lung PDE5: a strong basis for treating pulmonary hypertension with PDE5 inhibitors. Biochem Biophys Res Commun 2005;334:930-8.

11. Carter EA, Sheel AW, Milsom WK, et al. Sildenafil does not improve perfomance in $16.1 \mathrm{~km}$ cycle exercise time-trial in acute hypoxia. PLoS ONE. In Press.

12. Ghofrani HA, Reichenberger F, Kohstall MG et al. Sildenafil increased exercise capacity during hypoxia at low altitudes and at Mount Everest base cAMP. Ann Intern Med 2004;141:169-77.

13. Richalet J-P, Gratadour P, Robach P, et al. Sildenafil inhibits altitudeinduced hypoxemia and pulmonary hypertension. Am J Respir Crit Care Med 2005;171:275-81.

14. Hsu AR, Barnholt KE, Grundmann NK, et al. Sildenafil improves cardiac output and exercise performance during acute hypoxia, but not normoxia. J Appl Physiol 2006;100:2031-40.
15. Faoro V, Lamotte M, Deboeck G, et al. Effects of sildenafil on exercise capacity in hypoxic normal subjects. High Alt Med Biol 2007;8:155-63

16. Jacobs KA, Kressler J, Stoutenberg M, et al. Sildenafil has little influence on cardiovascular hemodynamics or 6-km time trial performance in trained men and women at simulated high altitude. High Alt Med Biol 2011;12:215-22.

17. Hozo SP, Djulbegovic B, Hozo I. Estimating the mean and variance from the median, range, and the size of a sample. BMC Med Res Methodol 2005;5:564-10.

18. Conkin J, Wessel JH. Critique of the equivalent air altitude model Aviat Space Environ Med 2008;79:975-82.

19. Hedges LV. Distribution theory for Glass's estimator of effect size and related estimators. JEB 2016;6:107-28.

20. Cohen J. Statistical power analysis for the behavioural sciences 1988.

21. Higgins JPT, Thompson SG, Deeks JJ, et al. Measuring inconsistency in meta-analyses. BMJ 2003;327:557-60.

22. Olfert IM, Loeckinger A, Treml B, et al. Sildenafil and bosentan improve arterial oxygenation during acute hypoxic exercise: a controlled laboratory trial. Wilderness Environ Med 2011;22:211-21.

23. Bates MGD, Thompson AAR, Baillie JK, et al. Sildenafil citrate for the prevention of high altitude hypoxic pulmonary hypertension: double blind, randomized, placebo-controlled trial. High Alt Med Biol 2011;12:207-14

24. Ricart A, Maristany J, Fort N, et al. Effects of sildenafil on the human response to acute hypoxia and exercise. High Alt Med Biol 2005;6:43-9.

25. Zhao L, Mason NA, Morrell NW, et al. Sildenafil inhibits hypoxiainduced pulmonary hypertension. Circulation 2001;104:424-8.

26. Lalande S, Snyder EM, Olson TP, et al. The effects of sildenafil and acetazolamide on breathing efficiency and ventilatory control during hypoxic exercise. Eur J Appl Physiol 2009;106:509-15.

27. Reichenberger F, Kohstall MG, Seeger T, et al. Effect of sildenafil on hypoxia-induced changes in pulmonary circulation and right ventricular function. Respir Physiol Neurobiol 2007;159:196-201.

28. Snyder EM, Olson TP, Johnson BD, et al. Influence of sildenafil on lung diffusion during exposure to acute hypoxia at rest and during exercise in healthy humans. Eur J Appl Physiol 2008;103:421-30.

29. Rodway GW, Lovelace AJ, Lanspa MJ, et al. Sildenafil and exercise capacity in the elderly at moderate altitude. Wilderness Environ Med 2016;27:307-15

30. Toro-Salinas AH, Fort N, Torrella JR, et al. Sildenafil does not improve exercise capacity under acute hypoxia exposure. Int $J$ Sports Med 2016;37:785-91.

31. Chapman RF. The individual response to training and competition at altitude. Br J Sports Med 2013;47(Suppl 1):i40-4.

32. Richard NA, Koehle MS. Differences in cardio-ventilatory responses to hypobaric and normobaric hypoxia: a review. Aviat Space Environ Med 2012:83:677-84. 